\title{
Prediction of Surface Roughness for CNC Turning of EN8 Steel Bar Using Artificial Neural Network Model
}

\author{
Abhishek Srivastava, Adarsh Sharma, Aditya Singh Gaur, Rahul Kumar, Yashwant Kumar Modi* \\ Department of Mechanical Engineering, Jaypee University of Engineering and Technology, Guna, MP 473226, India
}

Corresponding Author Email: yashwant.modi@juet.ac.in

https://doi.org/10.18280/jesa.520211

Received: 16 January 2019

Accepted: 9 March 2019

\section{Keywords:}

artificial neural network, design of experiment (DOE), predictive model, turning parameters, surface roughness

\begin{abstract}
Manufacturing organizations are under tremendous pressure to produce quality products at reduced manufacturing cost with shorter time-to-market. A good combination of process parameters for any manufacturing process may ensure production of quality parts at reduced time and cost. Aim of the present study is to develop an artificial neural network (ANN) model for CNC turning operation to predict surface roughness of EN8 bar for a specific set of parameters. In this study, effect of CNC turning parameters, namely spindle speed, depth of cut and feed rate, each with three levels, on surface roughness of EN8 steel bar has been studied experimentally. Total 27 experiments have been conducted as per full factorial design of experiment approach and surface roughness of the turned pieces is evaluated using a Mitutoyo make roughness tester. One set of the roughness values has been used to train the ANN model and another set is used to test the predictability of the model in MATLAB 8.0 software. The average error between the experimental and predicted values is found to be $7.85 \%$.
\end{abstract}

\section{INTRODUCTION}

In this world of cut-throat competition, significance of quality products has grown manifold. Producing quality products at reduced cost has become a challenge to manufacturing organization. Machining parameter not only affect the manufacturing cost and productivity but also quality of the final product. There are several parameters, which affect the surface roughness of a component and can be classified into four main groups, machining parameters, like spindle speed, feed rate, depth of cut etc., machining and machine tool conditions, like dry or wet turning, type of cutting fluid, cutting tool parameters, such as tool geometry, tool material, tool wear, tool nose radius and material properties of work piece [1]. Surface roughness can be optimized for given set of parameters using techniques such as Taguchi method, response surface method, genetic algorithm, ANN etc. [2-6]. Mathematical modeling of a process reduces the effort, save money and time for optimal and efficient implementation of any process. Many investigations have been made in this direction using ANN modeling; however, modeling is machine tool and process parameters specific and needs to be done for specific process.

Tsai et al. (1999) developed an ANN model to predict the surface roughness of End-milled part. An accelerometer and a proximity sensor were employed during cutting to collect the vibration and rotation data. Spindle speed, feed rate, depth of cut and the average vibration per revolution as input layer and surface roughness $\left(R_{a}\right)$ value as output layer were used for the ANN [7]. Karayel (2009) developed ANN model to Predict and control of surface roughness for steel on CNC lathe. He obtained average absolute error of $2.29 \%$ for ANN model and $10.75 \%$ absolute error for regression model [8]. Patel and $\mathrm{Pal}$ employed the Taguchi design method and ANOVA to optimize the surface roughness quality in milling of aluminium. They found that spindle speed is most and depth of cut is least significant parameter [9].

From the literature review, it was found that there are various techniques used for model preparation and surface roughness prediction like response surface methodology (RSM), Genetic algorithm (GA), Statistical regression technique, ANN etc. However, in all the cases, the efficiency and robustness of the model play an important role to predict the accurate results.

In this paper, authors have discussed the effect of machining parameters on surface roughness. The study has been carried out on computer numeric control (CNC) lathe "MCL10". The significant machining parameters namely spindle speed, feed rate and depth of cut were chosen to be optimized to get better surface finish of EN8 steel work-piece in turning operation. The objective of the present study is to develop an artificial neural network (ANN) model for CNC turning operation to predict surface finish of EN8 bar.

\section{WORKPIECE MATERIAL}

The experiment was performed on EN8 round steel bar having diameter of $25.4 \mathrm{~mm}$ and length $60 \mathrm{~mm}$. It is a medium strength steel and has good tensile strength. EN8 is can be used to manufacture parts like shafts, axles, gears for automobiles, hardened pins, keys etc. It can be induction hardened and used to produce parts which can bear higher wear resistance. Composition of EN8 steel is shown in Table 1.

Table 1. Chemical composition of EN8 steel

\begin{tabular}{cccccc}
\hline $\mathbf{C}$ & $\mathbf{M n}$ & $\mathbf{S i}$ & $\mathbf{P}$ & $\mathbf{S}$ & $\mathbf{F e}$ \\
\hline $0.35-$ & $0.60-$ & $0.05-$ & $0.06 \%$ & $0.06 \%$ & \multirow{2}{*}{ Balance } \\
$0.45 \%$ & $1.00 \%$ & $0.35 \%$ & $\max$ & $\max$ & \\
\hline
\end{tabular}




\section{DESIGN OF EXPERIMENT}

Design of Experiments (DOE) refers to the process of planning, designing and analyzing the experiment so that valid and objective conclusions can be drawn effectively and efficiently.

The methodology of DOE is fundamentally divided into four phases; 1) Planning phase: Problem recognition, formulation and selection of process and response parameters, determination of levels etc. 2) Designing phase: selecting the most appropriate design for the experiment, 3) Conducting phase: Conduction of experiments as per design and 4) Analysing phase: Analysis of results from different perspectives.

Factorial design enables an experimenter to study the joint effect of the factors on a response. A factorial design can be either full or fractional factorial. A full factorial design consists of all possible combinations of levels for all factors. Total number of experiments for studying $\mathrm{k}$ factors at $\mathrm{N}$-levels is $\mathrm{N}^{\mathrm{k}}$. In present work, three most influential turning parameters namely spindle speed, feed rate and depth of cut, each with three levels are selected as shown in Table 2. Full factorial design is chosen, so that a good number of results can be obtained to train and test the ANN model. Total $27\left(3^{3}\right)$ experiments were designed and conducted as shown in Table 3.

Table 2. Machining parameters with levels

\begin{tabular}{cccc}
\hline Parameters & Level 1 & Level 2 & Level 3 \\
\hline Spindle speed (rpm) & 1500 & 1700 & 1900 \\
Feed rate $(\mathrm{mm} / \mathrm{min})$ & 10 & 20 & 30 \\
Depth of cut $(\mathrm{mm})$ & 0.2 & 0.4 & 0.6 \\
\hline
\end{tabular}

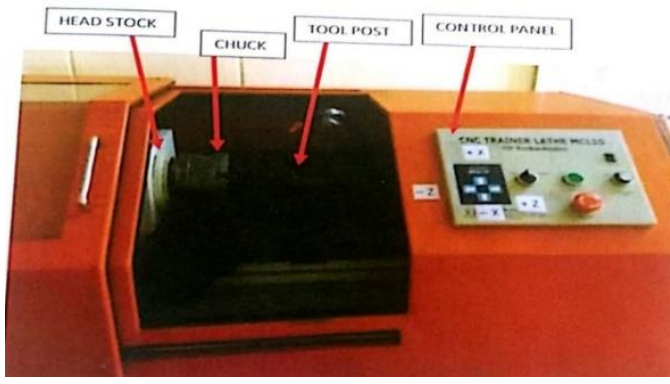

Figure 1. MCL10 Lathe, CIM Lab, JUET

\section{EXPERIMENTAL WORK}

Experiments were performed on CNC Lathe "MCL10" in wet machining condition. The work material used for this purpose was EN8 round steel and was turned using a tungsten carbide single point cutting tool.

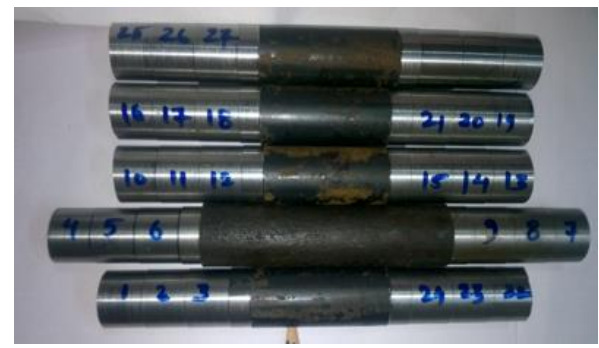

Figure 2. Photograph of EN8 Turned workpieces
The experimental setup consists of $\mathrm{CNC}$ lathe machine, power supply, and the whole setup is connected to the central computer. The tool used to perform machining was tungsten carbide having tool nose radius $8.66 \mathrm{~mm}$. The tool was checked periodically to ensure its opportune functioning. The cutting tool was cleaned to avoid any chip and Built-up edge (BUE) formation after machining of every specimen to ensure a good surface finish. Total 27 specimens were turned, as shown in Figure 2 as per the designed experiments shown in Table 3. Surface roughness measurement has been carried out using microprocessor-based Surfpak-Ez (Mittutoyo make) surface tester, shown in Figure 3. This tester gives results with high accuracy in three dimensional analyses. The measured values of surface roughness for all the 27 specimens have been given in Table 3 .

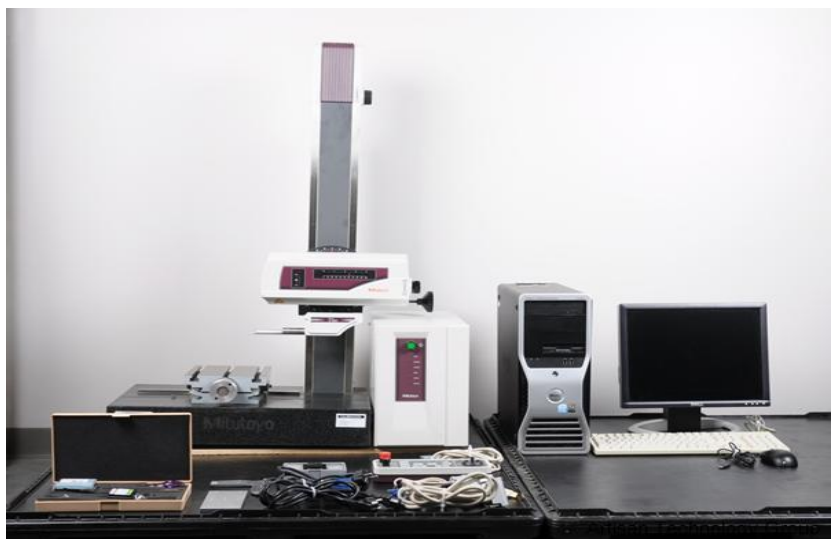

Figure 3. Photograph of Surfpak-Ez, surface tester

Table 3. Measured roughness values with designed experiments

\begin{tabular}{|c|c|c|c|c|}
\hline $\begin{array}{l}\text { S. } \\
\text { No. }\end{array}$ & $\begin{array}{c}\text { Spindle } \\
\text { speed } \\
(\mathrm{m} / \mathrm{min})\end{array}$ & $\begin{array}{l}\text { Feed rate } \\
(\mathrm{mm} / \mathrm{rev})\end{array}$ & $\begin{array}{l}\text { Depth } \\
\text { of cut } \\
(\mathrm{mm})\end{array}$ & $\begin{array}{c}\text { Roughness } \\
\text { value } \\
\mathbf{R}_{\mathbf{a}}(\boldsymbol{\mu m}) \\
\end{array}$ \\
\hline 1 & 1900 & 10 & 0.6 & 5.932 \\
\hline 2 & 1900 & 10 & 0.4 & 5.200 \\
\hline 3 & 1900 & 10 & 0.2 & 3.328 \\
\hline 4 & 1900 & 20 & 0.6 & 5.224 \\
\hline 5 & 1900 & 20 & 0.4 & 4.849 \\
\hline 6 & 1900 & 20 & 0.2 & 4.236 \\
\hline 7 & 1900 & 30 & 0.6 & 5.759 \\
\hline 8 & 1900 & 30 & 0.4 & 4.713 \\
\hline 9 & 1900 & 30 & 0.2 & 3.020 \\
\hline 10 & 1700 & 10 & 0.6 & 5.877 \\
\hline 11 & 1700 & 10 & 0.4 & 4.131 \\
\hline 12 & 1700 & 10 & 0.2 & 3.245 \\
\hline 13 & 1700 & 20 & 0.6 & 5.308 \\
\hline 14 & 1700 & 20 & 0.4 & 4.270 \\
\hline 15 & 1700 & 20 & 0.2 & 3.372 \\
\hline 16 & 1700 & 30 & 0.6 & 5.657 \\
\hline 17 & 1700 & 30 & 0.4 & 3.256 \\
\hline 18 & 1700 & 30 & 0.2 & 2.300 \\
\hline 19 & 1500 & 10 & 0.6 & 5.549 \\
\hline 20 & 1500 & 10 & 0.4 & 3.715 \\
\hline 21 & 1500 & 10 & 0.2 & 3.020 \\
\hline 22 & 1500 & 20 & 0.6 & 3.775 \\
\hline 23 & 1500 & 20 & 0.4 & 3.569 \\
\hline 24 & 1500 & 20 & 0.2 & 2.174 \\
\hline 25 & 1500 & 30 & 0.6 & 5.629 \\
\hline 26 & 1500 & 30 & 0.4 & 4.155 \\
\hline 27 & 1500 & 30 & 0.2 & 2.282 \\
\hline
\end{tabular}




\section{NEURAL NETWORK MODEL}

Artificial neural network (ANN) is an artificial intelligence tool for machine learning. ANN consists of input, hidden and output layers as shown in Figure 4.

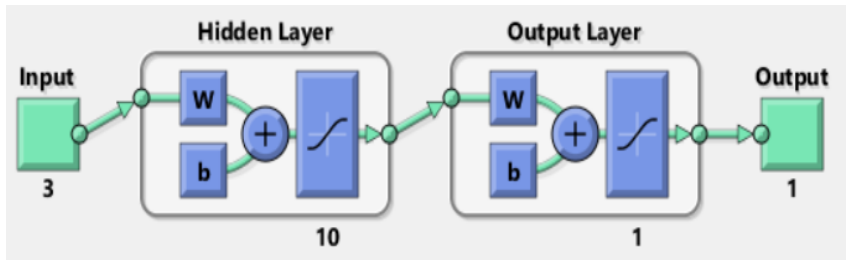

Figure 4. Artificial neural network model

Hidden layer consists of units which convert the input values into some intermediate values which are further used by output layer. Initially, a network is created in the training of a feed forward network [10-11]. The ANN knowledge in interconnection weights is adjusted during training process. Independent variables in the model is equal to input neurons, whereas the output neurons are in same number as the functions to be approximated. Here, inputs to the ANN model are the cutting parameters, namely depth of cut, feed rate and cutting speed. The ANN model output parameter is surface roughness. The input layer has three neurons, hidden layer has ten neurons and output layer has one neuron. ANN training and architectural parameters have to be appropriately selected so that an optimal ANN model for the prediction of surface roughness is developed [12]. The most elementary method for selection of parameter settings is the use of a trial and error method [13]. The most important training and architectural parameters are: learning rate, momentum, number of hidden layers, and number of neurons in hidden layer. The number of neurons in the hidden layer is a primary parameter of the ANN architecture. Due to the full interconnection used between neurons, any increase in the neuron number leads to increasing net complexity as well as training time. On the other hand networks with more neurons in the hidden layer may solve more complex problems. However, an ANN with too many hidden neurons will generalize very badly, which is a reflection of well-known over-fitting problem.

\section{RESULT AND DISCUSSION}

Total 27 specimens were turned as per the designed experiments and roughness value of each specimen was evaluated as discussed in previous section. An ANN model was designed. Out of the 27 readings, 20 were used for training purpose and the remaining 7 reading (as shown in Table 4) were used to check the accuracy of ANN model. ANN model was trained using MATLAB software. The screenshots of MATLAB are shown in Figure 5 and 6.

The seven roughness values shown in Table 4 were used to check the accuracy of the ANN model. The actual and predicted roughness values were compared and percentage error has also been shown in Table 4 .

The predicted surface roughness (output) and actual surface roughness (target) are shown in Figure 7 and percentage error recorded is shown in Figure 8.
Table 4. Predicted and actual surface roughness values with \% error

\begin{tabular}{|c|c|c|c|c|c|c|}
\hline 嶽 & 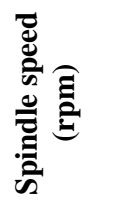 & 总 & 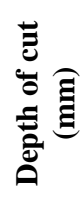 & 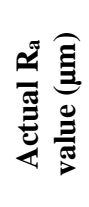 & 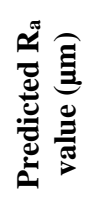 & 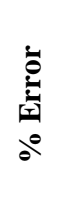 \\
\hline 13 & 1700 & 20 & 0.6 & 5.308 & 5.479 & -3.2 \\
\hline 14 & 1700 & 20 & 0.4 & 4.270 & 3.925 & 8.1 \\
\hline 15 & 1700 & 20 & 0.2 & 3.372 & 3.274 & 2.9 \\
\hline 16 & 1700 & 30 & 0.6 & 5.657 & 5.492 & 2.9 \\
\hline 19 & 1500 & 10 & 0.6 & 5.549 & 5.023 & 9.5 \\
\hline 20 & 1500 & 10 & 0.4 & 3.715 & 3.251 & 12.5 \\
\hline 21 & 1500 & 10 & 0.2 & 3.020 & 3.499 & -15.8 \\
\hline
\end{tabular}

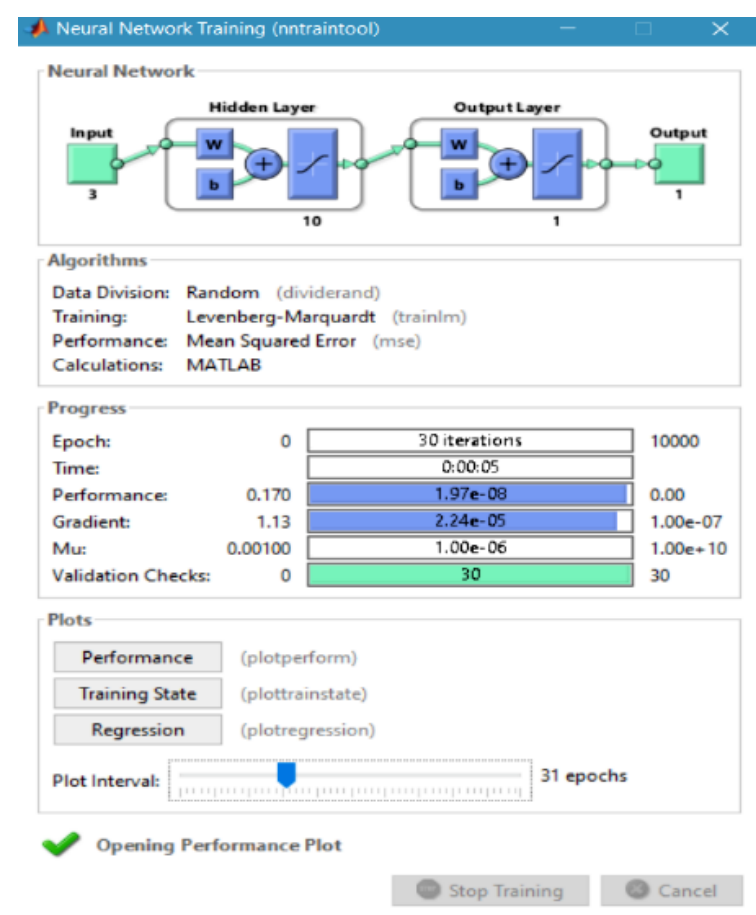

Figure 5. ANN training in MATLAB

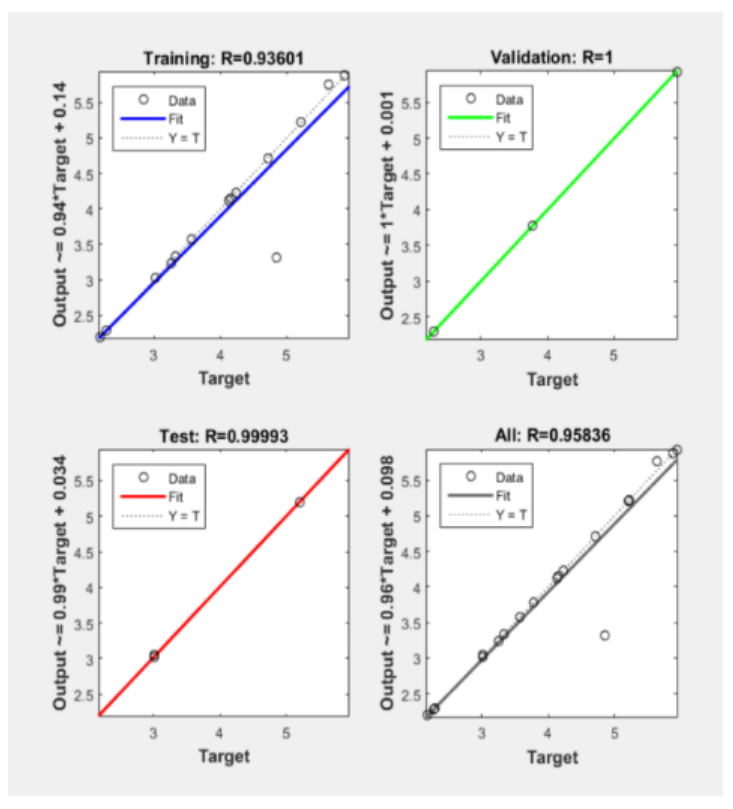

Figure 6. Regression curve 


\section{CONCLUSIONS}

The main objective of the present work was to develop an ANN model which can predict surface roughness of EN8 steel for a given set of cutting parameters namely speed, feed and depth of cut in CNC turning operation. Back-propagation feed forward neural network was used to develop the model to predict the surface roughness. Surface roughness prediction through developed ANN model has been done satisfactory with an average $7.85 \%$ error i.e. $92.15 \%$ accuracy in predicted values. The result is also comparable with previously available results. ANN model developed was reliable enough to predict the surface roughness. So, it can be concluded that ANN model provides a good prediction of surface roughness in $\mathrm{CNC}$ turning process.

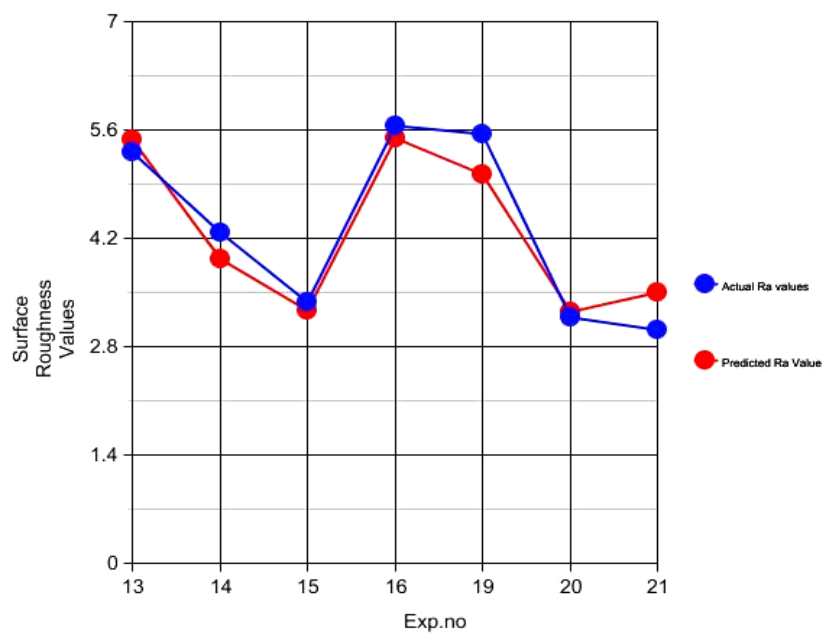

Figure 7. Actual vs. predicted $R_{a}$ graph

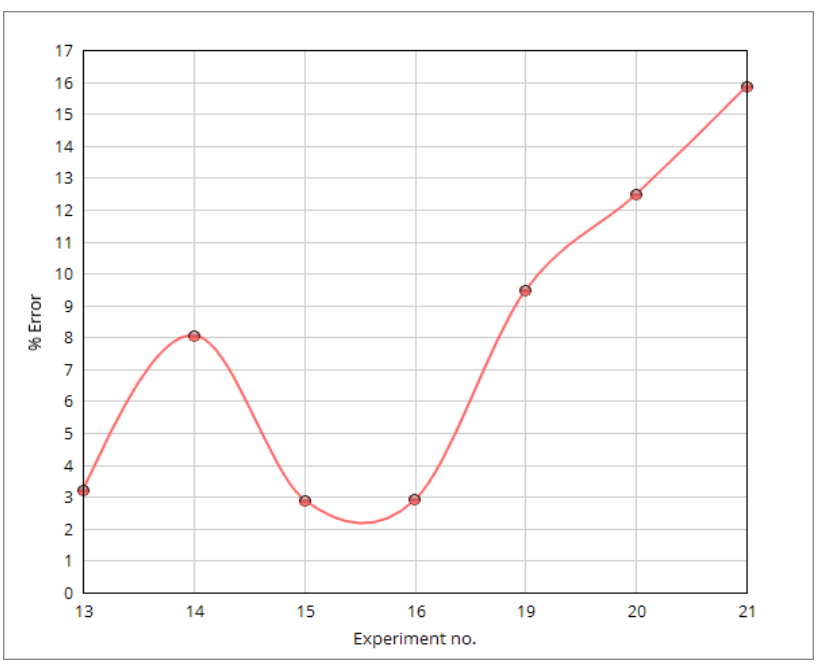

Figure 8. Percentage error graph

\section{REFERENCES}

[1] Groover, M.P. (2007). Fundamentals of modern manufacturing: Materials processes, and systems. John Wiley \& Sons.
[2] Yang, W.P., Tarng, Y.S. (1998). Design optimization of cutting parameters for turning operations based on the Taguchi method. Journal of Materials Processing Technology, $\quad 84(1-3)$ : 122-129. http://dx.doi.org/10.1016/S0924-0136(98)00079-X

[3] Suresh, P.V., Rao, P.V., Deshmukh, S.G. (2002). A genetic algorithmic approach for optimization of surface roughness prediction model. International Journal of Machine Tools and Manufacture, 42(6): 675-80. http://dx.doi.org/10.1016/S0890-6955(02)00005-6

[4] Srikanth, T., Kamala, V. (2008). A real coded genetic algorithm for optimization of cutting parameters in turning. International Journal of Computer Science and Network Security, 8(6): 189-193.

[5] Cus, F., Balic, J. (2003). Optimization of cutting process by GA approach. Robotics and Computer-Integrated Manufacturing, $\quad$ 19(1-2): http://dx.doi.org/10.1016/S0736-5845(02)00068-6

[6] Öktem, H., Erzurumlu, T., Kurtaran, H. (2005). Application of response surface methodology in the optimization of cutting conditions for surface roughness. Journal of Materials Processing Technology, 170(1-2): 11-16.

[7] Tsai, Y.H., Chen, J.C., Lou, S.J. (1999). An in-process surface recognition system based on neural networks in end milling cutting operations. International Journal of Machine Tools and Manufacture, 39(4): 583-605. http://dx.doi.org/10.1016/S0890-6955(98)00053-4

[8] Karayel, D. (2009). Prediction and control of surface roughness in $\mathrm{CNC}$ lathe using artificial neural network. Journal of Materials Processing Technology, 209(7): 3125-3137.

http://dx.doi.org/10.1016/j.jmatprotec.2008.07.023

[9] Patel, B.S., Pal, H. (2012). Optimization of machining parameters for surface roughness in milling operation. International Journal of Applied Engineering Research, 7(11): 2012.

[10] Villaseñor, D., Morales-Menendez, R., Rodrıguez, C., Alique, J.R. (2006). Neural networks and statistical based models for surface roughness prediction. In Proceedings of the 25th IASTED International Conference Modelling, Identification and Control, pp. 326-331.

[11] Hossain, M.I., Amin, A.N., Patwari, A.U. (2008). Development of an artificial neural network algorithm for predicting the surface roughness in end milling of Inconel 718 alloy. In Proceedings of International Conference on Computer and Communication Engineering, pp. 1321-1324. http://dx.doi.org/10.1109/ICCCE.2008.4580819

[12] Sakir, T., Süleyman, N., Ismail, S., Süleyman, Y. (2008). Prediction of surface roughness using artificial neural network in lathe. In Proceedings of 9th Int. Conf. on Computer Systems and Technologies and Workshop for $\mathrm{PhD}$ students in Computing.

[13] Zuperl, U., Cus, F. (2003). Optimization of cutting conditions during cutting by using neural networks. Robotics and Computer-Integrated Manufacturing, 19(12):

189-99. http://dx.doi.org/10.1016/S07365845(02)00079-0 